\title{
Differential expression of cancer associated proteins in breast milk based on age at first full term pregnancy
}

\author{
Wenyi Qin ${ }^{1}$, Ke Zhang ${ }^{2}$, Beth Kliethermes ${ }^{1}$, Rachel L Ruhlen ${ }^{3}$, Eva P Browne ${ }^{4}$, Kathleen F Arcaro ${ }^{4}$ and \\ Edward R Sauter ${ }^{1,5^{*}}$
}

\begin{abstract}
Background: First full term pregnancy (FFTP) completed at a young age has been linked to low long term breast cancer risk, whereas late FFTP pregnancy age confers high long term risk, compared to nulliparity. Our hypothesis was that proteins linked to breast cancer would be differentially expressed in human milk collected at three time points during lactation based on age at FFTP.

Methods: We analyzed breast milk from 72 lactating women. Samples were collected within 10 days of the onset of lactation (baseline-BL), two months after lactation started and during breast weaning (W). We measured 16 proteins (11 kallikreins (KLKs), basic fibroblast growth factor, YKL-40, neutrophil gelatinase-associated lipocalin and transforming growth factor (TGF) $\beta-1$ and -2) associated with breast cancer, most known to be secreted into milk.

Results: During lactation there was a significant change in the expression of 14 proteins in women $<26$ years old and 9 proteins in women $>=26$ at FFTP. The most significant $(p<.001)$ changes from BL to $W$ in women divided by FFTP age ( $<26$ vs. $>=26$ ) were in KLK3,6, 8, and TGF $\beta 2$ in women $<26$; and KLK6, 8, and TGF $\beta 2$ in women $>=26$. There was a significant increase $(p=.022)$ in KLK8 expression from BL to $W$ depending on FFTP age. Examination of DNA methylation in the promoter region of KLK6 revealed high levels of methylation that did not explain the observed changes in protein levels. On the other hand, KLK6 and TGF $\beta 1$ expression were significantly associated $\left(r^{2}=.43\right.$, $\mathrm{p}=.0050)$.
\end{abstract}

Conclusions: The expression profile of milk proteins linked to breast cancer is influenced by age at FFTP. These proteins may play a role in future cancer risk.

Keywords: Lactation, Breast cancer risk, First full term pregnancy, Milk proteins Funded in part by Avon Foundation for Women

\section{Background}

Immediately following parturition there is an increased risk of breast cancer observed for all age groups [1]. This is not surprising, since the growth factors required to allow breast glandular proliferation, as well as the extensive remodeling required during involution, may stimulate the growth of already present neoplastic mammary epithelial cell(s). Over the long term, parity is protective for women whose first full term pregnancy

\footnotetext{
* Correspondence: edward.sauter@med.und.edu

'Department of Surgery, University of North Dakota School of Medicine and Health Sciences, 501 N. Columbia Rd., Grand Forks, ND 58202, USA Full list of author information is available at the end of the article
}

(FFTP) was completed at a young age (variously defined as $<20$ up to age 26), and increased in parous women whose FFTP occurred after 35 years of age [2]. Rodent models suggest that early FFTP leads to changes in the pattern of breast lobular development and differentiation, cell growth, and gene expression [3]. Early FFTP imprints a specific genomic signature on the breast [3]. Most studies demonstrate a protective effect of breast feeding [4], though the influence of breast feeding duration on cancer risk is less clear, with a recent large study demonstrating no effect on risk of premenopausal breast cancer [5]. We think that breast cancer associated

C Biomed Central

(c) 2012 Qin et al; licensee BioMed Central Ltd. This is an Open Access article distributed under the terms of the Creative Commons Attribution License (http://creativecommons.org/licenses/by/2.0), which permits unrestricted use, distribution, and reproduction in any medium, provided the original work is properly cited. 
proteins can provide clues to how early FFTP confers a protective effect on the breast.

There is good evidence that during involution, which is initiated by weaning, the breast microenvironment becomes tumor promotional [6]. Our strategy was to identify protein biomarkers in breast milk that are associated with the protective effect of early FFTP vs. the cancer promoting effect of late FFTP. We have identified cancer associated proteins in breast nipple aspirate fluid, fluid from the milk ducts of nonlactating women, including kallikrein related peptidases (KLKs) $[7,8]$, basic fibroblast growth factor (bFGF) [9], and YKL-40 [10].

The KLK family consists of 15 highly conserved serine proteases. Several members of the family have been reported as potential cancer biomarkers [11], and many KLK genes are differentially expressed in hormone-related malignancies [12]. It has previously been demonstrated that multiple KLKs are detectable in breast milk [12]. Furthermore, the epigenetic regulation of KLK6 expression has been demonstrated in hormone sensitive (T47D) and insensitive (MDA-MB-231) malignant breast cells [13].

bFGF [14] has been detected in human milk, while YKL-40 (and its bovine homologue, mammary gland protein (MGP)-40) levels in breast milk rise during the time of breast involution, as the breast returns to the prepregnancy state [15]. Neutrophil gelatinase-associated lipocalin (NGAL, a.k.a. lipocalin 2) is a small secreted glycoprotein which binds matrix metalloproteinase-9 to protect it from degradation [16]. NGAL is expressed in breast carcinomas, inhibition of NGAL impairs breast tumorigenesis and metastasis [17], and increased NGAL expression has been associated with decreased diseasespecific survival [18]. The homolog of NGAL has been identified in cow's milk [19].

Transforming growth factor (TGF) $\beta$ is linked to breast cancer in preclinical models [20] and to prognosis in human breast cancer [21]. In mouse models, TGF $\beta$ is induced during mammary gland lactation and involution [20], and it mediates proapoptotic effects during involution [1]. Transgenic mice that overexpress TGF $\beta$ show increased apoptosis in the mammary epithelium throughout mammary development [22]. KLK6 is thought to act on the TGF $\beta 1$ signal transduction pathway and thereby influence cell migration and motility, and KLK6 alters the expression of TGF $\beta 1$ in breast cancer cells [23].

The time of weaning, a period of breast involution and remodeling, appears critical to future breast cancer risk [6]. The analysis of wean milk will provide essential information regarding the biology of markers related to breast involution. We investigated 16 proteins: $11 \mathrm{KLKs}$, bFGF, YKL-40, as well as NGAL and two isoforms TGF $\beta$, which, like bFGF and YKL-40, have been associated with breast cancer $[1,18]$. This study was conducted based on the hypothesis that lactation exerts a protective effect by upregulating cancer preventing and downregulating cancer promoting proteins in the breast based on age at FFTP.

\section{Methods}

\section{Recruitment}

Healthy women were prospectively recruited prior to or soon after delivery. They were eligible if they delivered a $\geq 37$ weeks gestation infant and were planning on breast feeding. After agreeing to enroll in an Institutional Review Board approved project, three milk samples were requested from each participant: baseline (BL), defined as within 10 days of the initiation of lactation, two months after lactation started, and when the woman is weaning (W). The participant was asked to provide the wean sample once they had decided to stop nursing, and had started to decrease the number of daily feedings. At least two samples from a given woman were required in order for the samples to be included in our analyses. Each sample was collected from the same breast.

Subjects were recruited in Columbia, MO, Grand Forks and Fargo, ND, after IRB approval. Mothers were asked not to breast feed their infants for at least two hours before milk collection, which involves draining the breast using manual extraction or a breast pump. Samples were immediately frozen after collection. Collected milk was thawed, centrifuged $\left(1500 \times \mathrm{g}, 20 \mathrm{~min}, 4^{\circ} \mathrm{C}\right)$, and the fat and cellular layers separated. The aqueous phase was then centrifuged at $12000 \mathrm{~g}$ for $15 \mathrm{~min}$ at $4^{\circ} \mathrm{C}$, the second lipid layer removed and stored at $-80^{\circ} \mathrm{C}$ prior to analysis.

\section{Assessment of protein biomarkers Total protein}

$25 \mu \mathrm{L}$ of standard and milk samples were added in duplicate to each microplate well (Pierce, Rockford, IL), followed by $200 \mu \mathrm{L}$ of working reagent with mixing. The microplate was then incubated at $37^{\circ} \mathrm{C}$ for 30 minutes and absorbance measured at $562 \mathrm{~nm}$.

KLKs

The concentration of KLKs was measured with a highly sensitive and specific non-competitive immunoassay. Each assay incorporated two KLK specific monoclonal and or polyclonal antibodies $(\mathrm{Ab})$, raised in mouse and rabbit respectively. One Ab was used for antigen capture and other for detection (Table 1) in a sequential two site immunometric format with time resolved fluorescence detection. KLK2 and KLK3 antibodies were obtained from MedixBiochemica (Kauniainen, Finland). The remaining KLK antibodies were developed in the laboratory of Dr. Eleftherios Diamandis Director of Clinical Biochemistry, University of Toronto. The KLK assays have a detection limit ranging from $0.005 \mu \mathrm{g} / \mathrm{L}$ for KLK3 to $0.2 \mu \mathrm{g} / \mathrm{L}$ for KLK7, 8 and 11 and a dynamic range of 10-20 $\mu \mathrm{g} / \mathrm{L}$, depending on the KLK (Table 1). These 
Table 1 Demographics and Kallikrein Assay Information

\begin{tabular}{|c|c|c|c|}
\hline Demographics & & & \\
\hline Total participants (N) & & 72 & \\
\hline First Full Term Pregnancy & & 35 & \\
\hline Multipara & & 37 & \\
\hline & $2^{\text {nd }}$ child & 25 & \\
\hline & $3^{\text {rd }}$ & 5 & \\
\hline & $4^{\text {th }}$ or greater & 7 & \\
\hline Age & & & \\
\hline & Mean (median) & $28.3(28)$ & \\
\hline & Range & $20-39$ & \\
\hline Kallikrein (KLK) Assay Inf & & & \\
\hline Kallikrein & Assay Configuration ${ }^{1}$ & Dynamic range & Detection Limit \\
\hline & & $(\mu \mathrm{g} / \mathrm{L})$ & $(\mu \mathrm{g} / \mathrm{L})$ \\
\hline KLK2 & Mono-Mono & 10 & 0.01 \\
\hline KLK3 & Mono-Mono & 10 & 0.005 \\
\hline KLK4 & Mono-Poly & 20 & 0.1 \\
\hline KLK5 & Mono-Mono & 10 & 0.05 \\
\hline KLK6 & Mono-Mono & 20 & 0.05 \\
\hline KLK7 & Mono-Mono & 20 & 0.2 \\
\hline KLK8 & Mono-Mono & 20 & 0.2 \\
\hline KLK10 & Mono-Mono & 10 & 0.1 \\
\hline KLK11 & Mono-Poly & 20 & 0.2 \\
\hline KLK13 & Mono-Mono & 10 & 0.1 \\
\hline KLK14 & Mono-Poly & 10 & 0.1 \\
\hline
\end{tabular}

1: Assay configuration: The confirmation listed indicates the two antibodies (Ab) used, the first being the antigen capture and the second the detection antibody. Mono: monoclonal $\mathrm{Ab}$, poly: polyclonal $\mathrm{Ab}$

assays have been used in multiple prior publications [8,12,24-27]. Standards (recombinant KLK) and samples were analyzed in duplicate with inclusion of three quality control samples in every run.

bFGF

bFGF was analyzed using an enzyme linked immunosorbant assay (ELISA) kit from R\&D Systems (Minneapolis, $\mathrm{MN})$, following the manufacturer's instructions. The kit utilizes a quantitative sandwich enzyme immunoassay technique. The detection limit of the kit is $10 \mathrm{ng} / \mathrm{L}$.

YKL-40

Samples were analyzed by immunoassay as per the manufacturer's instructions (Quidel Corporation, San Diego, CA). The kit uses a monoclonal anti-YKL-40 antibody conjugated to biotin which binds to streptavidin and captures YKL-40 in the standard or sample. The detection limit is $10 \mathrm{ng} / \mathrm{mL}$.

NGAL

NGAL content in milk was measured by immunoassay (BiPorto Diagnostics, Denmark) according to the manufacturer's instructions. Briefly, $100 \mu \mathrm{L}$ of standard and diluted milk samples were added to wells coated with a monoclonal antibody against human NGAL. Bound
NGAL was detected with a second antibody labeled with biotin and the signal developed with horseradish peroxidase-conjugated streptavidin and substrates, the reaction ended with stop solution and absorbance measured at $450 \mathrm{~nm}$. The detection limit of the NGAL kit is $4.0 \mathrm{pg} / \mathrm{mL}$.

\section{TGF $\beta$ isoforms}

The protein expression levels of TGF $\beta 1$ and $\beta 2$ in milk samples were determined by immunoassay (R\&D Systems) following the manufacturer's instructions. Briefly, $50 \mu \mathrm{L}$ of standard and activated milk samples were added to wells in duplicate, incubated for 2 hours at room temperature (RT), washed and $100 \mu \mathrm{L}$ of TGF $\beta 1$ or $\beta 2$ conjugate added. Following another wash, $100 \mu \mathrm{L}$ of substrate solution was added for $30 \mathrm{~min}$ at $\mathrm{RT}$, the reaction ended with $100 \mu \mathrm{L}$ of stop solution and absorbance measured at $450 \mathrm{~nm}$. The detection limits of the TGF $\beta 1$ and $\beta 2$ kits are 4.61 and $7.0 \mathrm{pg} / \mathrm{ml}$, respectively.

\section{Assessment of KLK6 methylation DNA Isolation and bisulfite treatment}

DNA was isolated from all 42 breast milk cell pellets that were available from women who underwent KLK6 
protein analysis women using the QIAamp DNA mini kit (Qiagen, Germantown MD) with the following modifications: $10 \mu \mathrm{l}$ of RNAse A (1 mg/ml) was added to each DNA isolation at the beginning of the protocol; at the end of the protocol an ethanol precipitation was performed to clean and concentrate the DNA. DNA quantity and quality were assessed using the NanoDrop 8000 spectrophotometer (Thermo Scientific, Wilmington DE). Up to $500 \mathrm{ng}$ of high quality DNA were bisulfite converted using the EpiTect Bisulfite Kit according to manufacturer's instructions (Qiagen, Germantown MD).

\section{KLK6 PCR and pyrosequencing}

Two $\mu$ l of bisulfite converted DNA were used in each PCR reaction to amplify the promoter region of the KLK6 gene using the PyroMark PCR kit (Qiagen, Germantown MD). KLK6 primers were designed to amplify an area of the promoter region upstream of the transcriptional start site (TSS). This region includes 4 CpG sites $(-72,-64,-56$ and -53 upstream of TSS) that have been shown to be methylated in breast cancer cell lines and unmethylated in normal cell lines [13]. Primer sequences are as follows: sense primer: 5'- GTAAAGGAGGATTGTTAGATAGGG-3', antisense primer: 5'-biotin-CCAACACCCCAATACCAT3', sequencing primer: 5'-GATAAAAGGAAGTTATTGATG-3'. Pyrosequencing was performed using a PyroMark Q24 pyrosequencer (Qiagen, Germantown MD) [28] using PyroGold Reagents (Qiagen, Germantown MD). Pyrosequencing using mixtures of in vitro methylated and unmethylated DNA demonstrated a high degree of linearity $\left(R^{2}=0.99\right)$ for this KLK6 DNA methylation assay.

\section{Statistical analysis}

Expression levels of proteins were first logarithm-transformed using natural base prior to analysis. Changes in protein expression over three time points (BL, 2 months, $\mathrm{W})$ were tested with longitudinal analysis using a linear mixed model. P values were adjusted for multiple tests with Holm's step-down procedure. For proteins that showed a significant change over the three time points, a paired $t$ test was performed to detect the change between each pair of time points. Regression analysis was carried out to identify the association between the ages at FFTP with BL protein levels or change of protein expression between the three lactation periods. In order to identify the maximum number of possible associations with FFTP, we did not adjust $\mathrm{p}$ values for multiple tests. The effects of nursing time on total protein and individual proteins were assessed using regression analysis. Levels of KLK6 methylation were compared among the three time points using one-way analysis of variance. The association of KLK6 methylation and protein levels was tested using regression analysis at each time point and at each CpG site. The interaction of KLK6 and TGF $\beta 1$ was analyzed using regression analysis.

\section{Results}

Breast milk samples were collected from 72 women, 35 women for whom it was their FFTP and 37 for whom it was not (Table 1). One woman enrolled in the study after breastfeeding for 2 months and no BL milk was available. A 2 month milk sample was not collected from two women because they weaned prior to the 2 month time point. Milk was collected at all three timepoints from 47 women. Wean milk samples were not collected from 25 women (14 have not yet weaned, 9 weaned but did not provide a wean sample, and 2 were lost to follow-up).

There was considerable variability between samples in total milk protein concentration. For this reason, all biomarker results are listed and all statistical analyses were conducted controlling for total protein concentration in the milk sample. Total protein expression was not influenced by either age at FFTP or whether the samples were collected from a primiparous vs. a multiparous woman. FFTP age was not found to interact with parity status.

\section{The expression of multiple milk proteins varies during the course of lactation}

For our two milk collection time points, overall (considering all sample collections) change in individual protein expression was compared in women with young $(<26$ years) vs. older ( $>=26$ years) age at FFTP (Table 2 ). Of the 16 proteins evaluated, there was an overall change in the expression of 14 (for women < 26) and 9 (for women $>=26)$ proteins, respectively.

For proteins with a significant global change, we determined (Table 2) the change for each of three lactation periods (BL to 2 months, BL to $\mathrm{W}$ and 2 months to $\mathrm{W}$ ). Mean expression significantly decreased for 8 (for women $<26$ ) and 8 (for women $>=26$ ) proteins, respectively, between $\mathrm{BL}$ and 2 months, and increased for 13 (for women $<26$ ) and 11 (for women $>=26$ ) proteins, respectively, between 2 months and W. Between BL and W there was a highly significant $(\mathrm{p}<.001)$ increase in the expression of KLK6, 8, and TGF $\beta 2$ in both age groups. KLK3 expression was lower in W than BL milk of women $<26$ but not those in the $>=26$ group.

\section{Expression (and expression change during lactation) of biomarkers linked to breast cancer are related to age at FFTP}

For each of the 16 proteins, we evaluated the association of expression with age at FFTP. At BL, bFGF $(\mathrm{p}=.0116)$ and NGAL ( $\mathrm{p}=.012)$ expression were significantly higher in women who were older at the time of their FFTP (Figure 1a,b). There were no significant associations at 
Table 2 Mean Natural Log (ng/g) Values of Baseline (BL), 2 Month (2 Mo) and Wean (W) Samples vs.

\begin{tabular}{|c|c|c|c|c|c|c|c|c|c|c|}
\hline Age (yrs) & $<26$ & & & & & $>=2$ & & & & \\
\hline Biomarker & $\mathrm{BL}$ & $2 \mathrm{Mo}$ & W & $\mathrm{P}$ (overall) & $P$ (pairs) $^{1}$ & $\mathrm{BL}$ & $2 \mathrm{Mo}$ & W & P (overall) & $P$ (pairs) $^{1}$ \\
\hline KLK2 & 0.91 & 0.96 & 0.89 & $\mathrm{NS}^{2}$ & $N S^{2}$ & 1.03 & 1.09 & 0.93 & NS & NS \\
\hline KLK3 & 2.36 & 1.75 & 0.80 & 0.0011 & ${ }^{*}$, ,十十 & 2.42 & 1.56 & 1.89 & NS & * \\
\hline KLK4 & -0.75 & -0.68 & 0.13 & 0.0088 & $\dagger, \wedge$ & -0.88 & -0.65 & -0.09 & NS & t十 \\
\hline KLK5 & 8.51 & 7.83 & 9.17 & 5.49E-11 & ${ }^{* *}, \wedge \wedge$ & 8.43 & 7.21 & 8.92 & $1.22 \mathrm{E}-10$ & $* * *, \wedge \wedge \wedge$ \\
\hline KLK6 & 9.88 & 10.1 & 10.9 & 4.61E-11 & 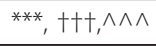 & 9.79 & 9.89 & 10.6 & $1.56 \mathrm{E}-6$ & †十ナ,^^^ \\
\hline KLK7 & 5.52 & 4.45 & 6.18 & 0.0039 & $* *, \wedge \wedge$ & 5.03 & 4.79 & 5.25 & NS & NS \\
\hline KLK8 & 8.10 & 8.32 & 9.54 & $5.16 \mathrm{E}-10$ & 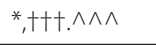 & 7.84 & 8.20 & 9.04 & $1.49 \mathrm{E}-10$ & ***, †十, $\wedge \wedge \wedge$ \\
\hline KLK10 & 5.18 & 5.97 & 7.18 & 0.0011 & $* * *,+十, \wedge \wedge$ & 4.77 & 5.59 & 7.15 & $2.3^{-4}$ & $*,+\dagger, \wedge \wedge$ \\
\hline KLK11 & 6.44 & 4.73 & 6.57 & $5.35 \mathrm{E}-5$ & $* * *, \wedge$ & 6.36 & 4.95 & 5.78 & 0.0049 & $* *$ \\
\hline KLK13 & 2.56 & 1.87 & 1.25 & NS & $\dagger, \wedge$ & 2.11 & 2.01 & 1.14 & NS & NS \\
\hline KLK14 & 1.10 & 0.89 & 1.46 & 0.046 & $\dagger+, \wedge \wedge$ & 1.18 & 0.83 & 1.21 & NS & $\wedge \wedge$ \\
\hline $\mathrm{N}$ (all KLKs) & 37 & 36 & 20 & & & 32 & 33 & 21 & & \\
\hline YKL40 & 12.1 & 10.6 & 12.2 & $2.38 \mathrm{E}-6$ & $* * *, \wedge \wedge$ & 12.3 & 10.1 & 12.0 & $3.88 \mathrm{E}-11$ & ${ }^{* * *}, \wedge \wedge \wedge$ \\
\hline NGAL & 8.31 & 7.23 & 8.37 & $4.5 \mathrm{E}-4$ & ${ }^{* * *}, \wedge \wedge$ & 8.91 & 7.16 & 8.36 & $6.96 \mathrm{E}-12$ & ${ }^{* * *}, \wedge \wedge \wedge$ \\
\hline bFGF & -1.46 & -3.15 & -1.91 & $2.58 \mathrm{E}-8$ & ${ }^{* * *}, \wedge \wedge \wedge$ & -1.07 & -2.89 & -1.85 & NS & ${ }^{* * *},+十, \wedge \wedge$ \\
\hline TGF $\beta 1$ & 3.88 & 3.52 & 4.23 & $5.49 \mathrm{E}-5$ & $* *, \wedge \wedge$ & 3.88 & 3.36 & 4.40 & $2.34 \mathrm{E}-5$ & $* *, \dagger, \wedge \wedge \wedge$ \\
\hline TGF $\beta 2$ & 5.55 & 5.25 & 7.06 & 7.27E-7 & $\dagger \dagger+, \wedge \wedge \wedge$ & 5.47 & 5.03 & 7.09 & $2.74 \mathrm{E}-12$ & ${ }^{*}$, $† \dagger, \wedge \wedge \wedge$ \\
\hline $\mathrm{N}($ non-KLKs) & 37 & 36 & 21 & & & 34 & 34 & 26 & & \\
\hline
\end{tabular}

Age at First Full Term Pregnancy

1: P (pairs): paired comparisons. *: BL vs. 2 Mo; $\dagger: B L$ vs. $W ; \wedge: 2$ Mo. vs. W. One mark $\left({ }^{*}, \dagger\right.$, or $\wedge$ ): $p<0.05 ;$ two marks: $p<0.01 ;$ three marks: $p<0.001$. P values adjusted for multiple comparisons using Holm's step-down procedure

2: NS: not significant. If NS is listed under P (pairs), it indicates that there were no significant associations for any of the three paired comparisons

2 months or W. There was a larger increase in KLK8 expression ( $\mathrm{p}=.022)$ from BL to W (controlling for total time that a woman nursed) with younger age at FFTP (Figure 1c).

DNA methylation of KLK6 varies among women and with breast feeding duration but does not explain protein expression pattern

To determine the extent to which the changes observed in KLK6 protein levels were controlled by epigenetc events, we isolated DNA from a total of 42 breast milk cell pellets (eight at BL, 13 at 2 months and 21 at W) obtained from 32 women. Methylation analysis by pyrosequencing revealed high mean levels of KLK6 promoter methylation at all three time points $57 \%$ (BL), 34\% (2 months) and 48\% $(\mathrm{W})$, and no significant differences across time points $(\mathrm{F}=$ $2.27 ; \mathrm{p}=.117)$. Among the ten women for whom methylation was assessed at two time points, there was an average absolute difference of $37 \%$ methylation between the two sampling times. The greatest differences (Figure 2)
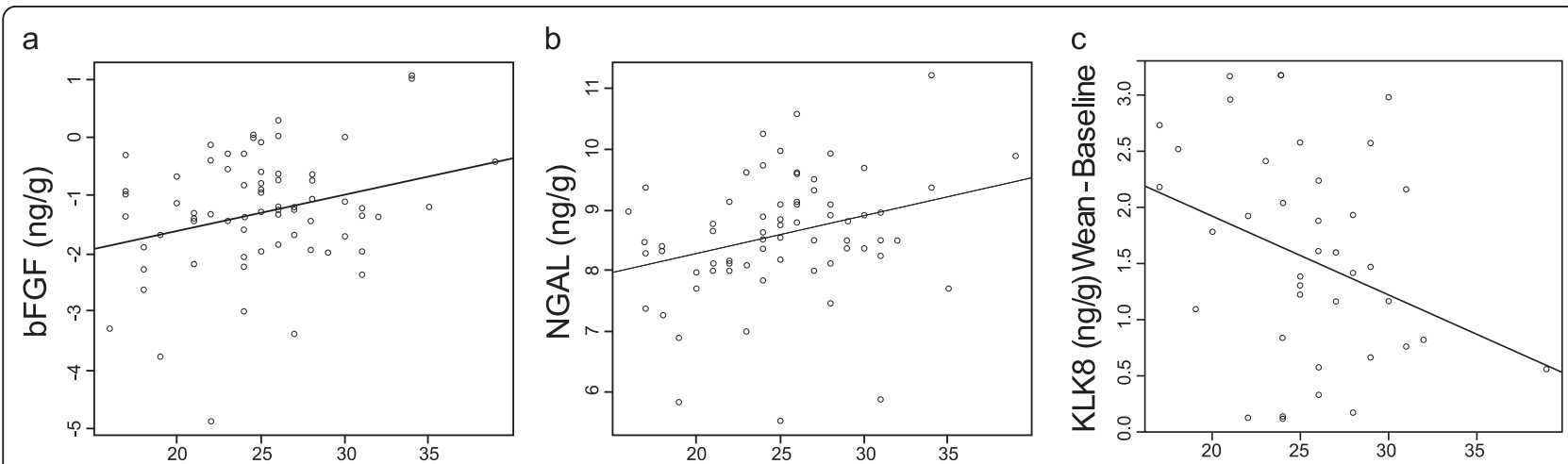

Age at FFTP

Figure 1 Natural log a) bFGF and b) NGAL baseline milk expression; or c) change (wean-baseline) in natural log KLK8 milk protein expression based on age at FFTP. For KLK8, only matched samples are represented. 
occurred between $\mathrm{BL}$ and 2 months (mean change for the 6 women $=44 \%$ ) and between 2 months and $\mathrm{W}$ (mean change for the two women $=42 \%$ ) with little change between $\mathrm{BL}$ and $\mathrm{W}$ (mean change for the two women = $10 \%)$. The methylation level was not associated with KLK6 protein level $(\mathrm{p}=.35)$.

\section{Association of KLK6 with TFG $\beta 1$}

KLK6 has been reported to interact with the TGF $\beta 1$ signal transduction pathway and influence TGF $\beta 1$ expression in breast cancer cells [23]. We determined the association of these proteins in breast milk, considering all samples for which there were paired values. The two proteins (Figure 3$)$ were significantly associated $\left(r^{2}=\right.$ $.43, \mathrm{p}=.0050)$.

\section{Discussion}

One approach to assess the influence of a specific process such as age at FFTP is global (proteome wide) assessment. Unfortunately, this approach has limited sensitivity [29] even with sample concentration approaches [30], and lack reliable quantitation of individual protein concentration. We elected to use immunoassays which are highly sensitive and quantitative, to compare individual protein expression during the course of lactation.

A striking feature of the data is that the expression of most proteins varies during lactation, even after controlling for total protein concentration. A similar observation in a smaller sample was made by another group in the assessment of milk immunoglobulins and lysozyme [31]. The most common trend that we observed was for the concentration of proteins to decrease from BL to 2 months after starting nursing, and then to increase between 2 months and W. Although the reason(s) for this are uncertain, a possible explanation is that the breast secretes a given amount of each protein daily, with greater milk volume during the 2 month lactation period compared to $\mathrm{BL}$ or $\mathrm{W}$ periods leading to a lower protein concentration. Indeed, total milk protein concentration has been shown to negatively correlate with 24 hour milk volume [32], and gradual weaning over a period of three months has been shown to increase total protein as milk volume decreased [33].

The most significant changes in expression from the start to the end of lactation in both FFTP age groups were in KLK6, 8 and TGF $\beta 2$. There was a significant decrease in KLK3 in women $<26$ at the time of FFTP, but not in

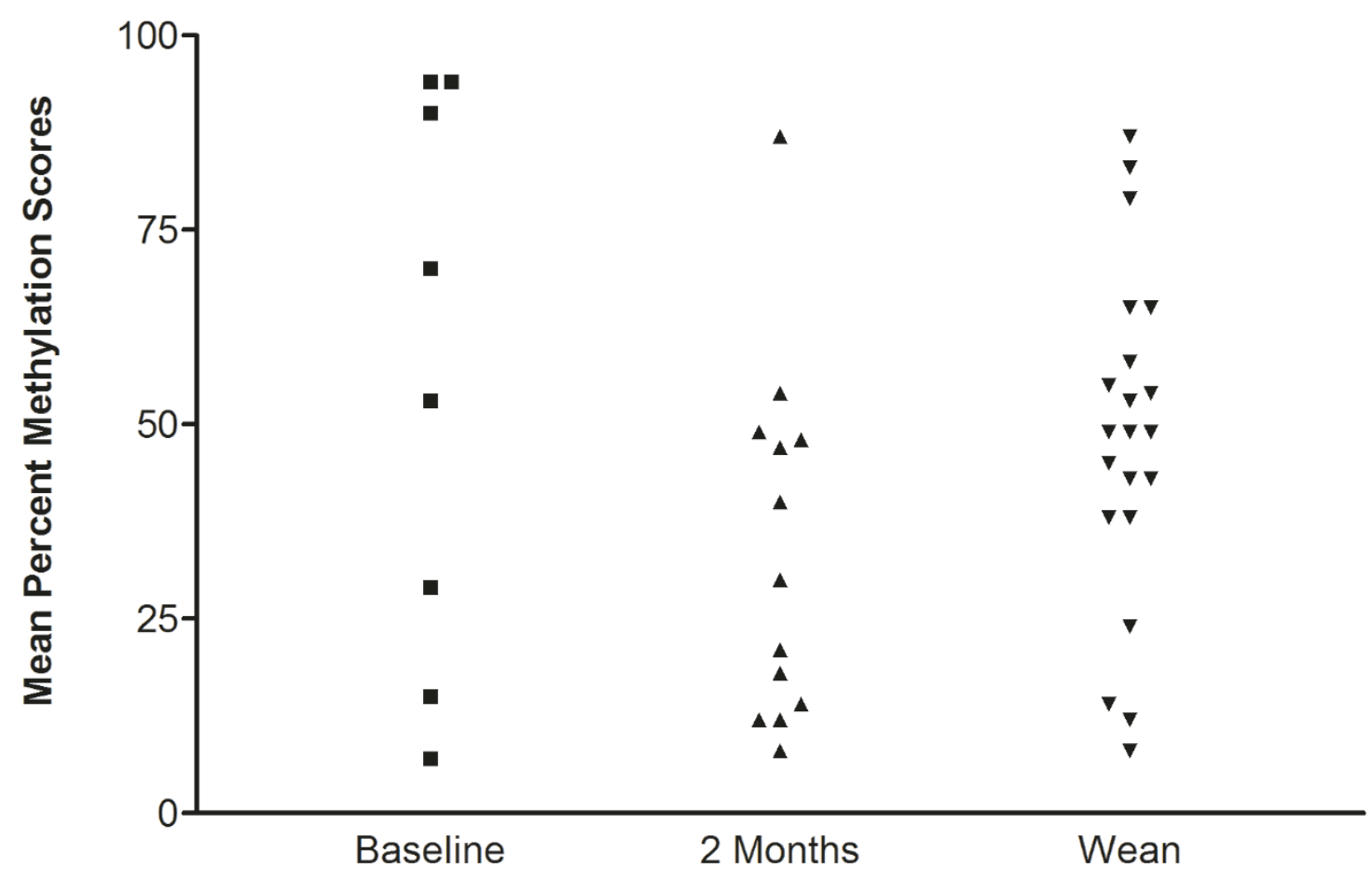

Figure 2 Methylation of KLK6 in DNA isolated from cells obtained from breast milk. The average of the percent of methylated DNA at each of 4 CpG sites in the proximal promoter of KLK6 is shown for milk samples collected at Baseline $(n=8)$, Two Months $(n=13)$, and Wean $(n=21)$. 


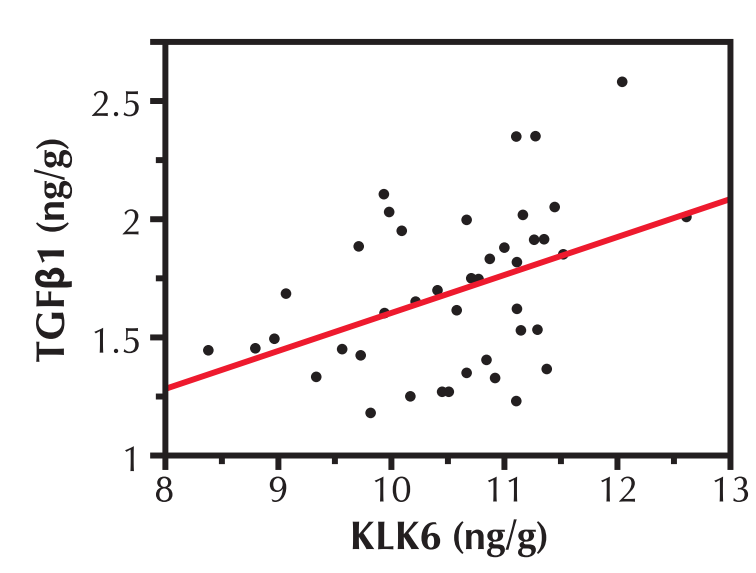

Figure 3 Association of natural log TGF $\beta 1$ and KLK6 protein expression in breast milk.

women with a later age of FFTP. The significance of the change in one but not the other group is uncertain. For KLK6, 8 and TGF $\beta 2$, there was a small change early (between $\mathrm{BL}$ and 2 months), with a larger change later (between 2 months and W) in lactation. For all three proteins there was an increase in mean expression at the time of weaning compared to BL.

KLK6 and 8 expression is downregulated in breast cancers [34]. As such, it has been speculated that these genes may function to suppress tumors [13]. KLK6 [13] is epigenetically regulated with gene silencing in tumors. KLK6 may play a protective role against tumor progression by inhibiting the epithelial-to-mesenchymal transition [13]. KLK8 has been shown to function as a serine protease [35]. The mechanism of KLK8 gene silencing in breast cancer has not been reported, though alternative splice variants of the gene which influence prognosis have been reported in lung cancer [36]. The increase in KLK8 expression from $\mathrm{BL}$ to $\mathrm{W}$ was greatest in women who whose FFTP occurred at a young age, which is consistent with known protective effect of early age at FFTP [2] and a tumor suppressive effect of KLK8.

The significant changes in KLK6 protein expression during lactation and the report of regulation of KLK6 by methylation in breast cancer cells [13] prompted us to examine KLK6 promoter methylation in cells obtained from breast milk. We detected surprisingly high levels of KLK6 promoter methylation with moderate differences among the three sampling times that did not explain the observed changes in protein expression. Indeed, the lowest mean level of methylation, 34\%, occurred at 2 months. While we expected low methylation to be associated with the highest protein expression, KLK6 expression, on average, was highest in wean milk for all age categories (Table 2). Whereas methylation scores were relatively high at all sampling times, repeated measures from ten women revealed average methylation changes during lactation of $37 \%$.

To assess the likelihood that the observed variability in KLK6 methylation throughout lactation was an artifact, we examined the promoter methylation of $p 16$ (data not shown), which we would not predict to vary with lactation duration. In contrast to KLK6, there was little methylation of p16 at each point, ranging from 1 to $5 \%$, indicating that the variability in KLK6 methylation is not likely to be an artifact. It is important to note that, unlike the prior report associating KLK6 methylation with KLK6 expression in cultured malignant breast cells [13], our clinical investigation evaluated breast cells collected from the breasts of healthy women. Regarding the variability in KLK6 methylation which we observed, we believe that this is at least partly due to differing percentages of epithelial cells and leucocytes that were present in the milk at the three sampling times, since DNA was isolated from the total cell pellet. Nonetheless, we confirmed that epithelial cells present in milk from healthy breasts have high levels of methylation by examining several epithelial-enriched cell fractions (data not shown).

Whereas we did not find a association between KLK6 methylation and protein expression, we did observe a highly significant association between KLK6 and TGF $\beta 1$ protein expression. TGF $\beta$ s regulate normal breast development, apoptosis and matrix remodeling during breast involution induced by breast weaning, with biphasic effects on tumor progression, acting as tumor suppressors in early stages of cancer and promoting invasion and metastasis at later stages [37]. Our observation that the expression of these proteins are directly correlated, whereas they are inversely associated in breast cancer cells in culture [23], is consistent with the pleiotropic effects of these molecules to suppress cancer initiation and promote later stages of cancer invasion and metastasis.

This report has limitations. Most notable is the limited sample of women whose FFTP was age 35 or greater, as well as the limited BL and 2 month sample sizes for the methylation analyses. We may have missed associations with age at FFTP due to this. A second limitation is that there was some variability between when the wean milk sample was collected and when the woman stopped nursing entirely. A third limitation is that we cannot say with certainty that the proteins identified which are upregulated at the time of weaning would put these women at lower risk of future breast cancer, since we do not have sufficient follow-up to address this. On the other hand, as previously discussed, we know from other reports that higher expression of KLK 6, 8, 10 and TGF 2 have been associated with a lower risk of breast cancer $[34,38]$. 


\section{Conclusions}

We report the upregulation of KLK 6, 8 and TGF $\beta 2$ at the time of breast weaning and involution. All four proteins have a tumor suppressive effect, consistent with the known protective effect of pregnancy in younger women. KLK8 levels were generally lower at BL in women older at the time of their FFTP, but the change was greater in these women, suggesting a protective correction toward a higher KLK8 expression level by the end of lactation. bFGF and NGAL expression was higher in BL lactation samples among women with an older age of FFTP. Both are tumor promotional, consistent with the association of late FFTP with increased breast cancer risk. Finally, we observed a significant association between KLK6 and TGF $\beta 1$, which may be one mechanism by which these molecules interact during lactation to influence future breast cancer risk. We plan to investigate these proteins in the nipple aspirate fluid of women with and without breast cancer, to see if their expression is associated with disease.

\section{Abbreviations}

BL: Baseline; bFGF: Basic fibroblast growth factor; ELISA: Enzyme linked immunosorbant assay; FFTP: First full term pregnancy; KLK: Kallikrein related peptidase; MGP: Mammary gland protein; NGAL: Neutrophil gelatinaseassociated lipocalin; RT: Room temperature; TGF: Transforming growth factor; TSS: Transcriptional start site; W: Wean.

\section{Author details}

'Department of Surgery, University of North Dakota School of Medicine and Health Sciences, 501 N. Columbia Rd., Grand Forks, ND 58202, USA. ${ }^{2}$ Department of Pathology, University of North Dakota School of Medicine and Health Sciences, 501 N. Columbia Rd., Grand Forks, ND 58202, USA. ${ }^{3}$ AT Still University Research Institute, 800 W. Jefferson St., Kirksville, MO 63501, USA. ${ }^{4}$ University of Massachusetts at Amherst, 637 North Pleasant Street, Amherst, MA 01003, USA. ${ }^{5}$ Health Sciences Department of Surgery, University of North Dakota School of Medicine, Rm 5092, Grand Forks, ND 58202, USA.

\section{Authors' contributions \\ WQ conducted total and individual protein assessment on all samples. KZ performed statistical analysis for the study. BK managed and provided quality assurance of the data analyzed. RLR assisted with preliminary data analysis and provided critical review of the manuscript. EPB performed methylation analysis and manuscript review. KFA oversaw methylation analysis and provided manuscript review. ERS initiated the study, oversaw the conduct of the entire project, enrolled participants, and prepared the manuscript for publication. All authors read and approved the final manuscript.}

\section{Competing interests}

Dr Sauter is a consultant for Atossa Genetics, Inc.

Received: 17 October 2011 Accepted: 21 March 2012

Published: 21 March 2012

\section{References}

1. Flanders KC, Wakefield LM: Transforming growth factor-(beta)s and mammary gland involution; functional roles and implications for cancer progression. J Mammary Gland Biol Neoplasia 2009, 14(2):131-144.

2. Medina D: Breast cancer: the protective effect of pregnancy. Clin Cancer Res 2004, 10(1 Pt 2):380S-384S.

3. Balogh GA, Heulings R, Mailo DA, Russo PA, Sheriff F, Russo $\mathbb{H}_{\text {, Moral R, }}$ Russo J: Genomic signature induced by pregnancy in the human breast. Int J Oncol 2006, 28(2):399-410.
4. Newcomb PA, Storer BE, Longnecker MP, Mittendorf R, Greenberg ER, Clapp RW, Burke KP, Willett WC, MacMahon B: Lactation and a reduced risk of premenopausal breast cancer. N Engl J Med 1994, 330(2):81-87.

5. Stuebe AM, Willett WC, Xue F, Michels KB: Lactation and incidence of premenopausal breast cancer: a longitudinal study. Arch Intern Med 2009, 169(15):1364-1371.

6. Schedin P, O'Brien J, Rudolph M, Stein T, Borges V: Microenvironment of the involuting mammary gland mediates mammary cancer progression. J Mammary Gland Biol Neoplasia 2007, 12(1):71-82.

7. Sauter ER, Daly M, Linahan K, Ehya H, Engstrom PF, Bonney G, Ross EA, $\mathrm{Yu}$ H, Diamandis E: Prostate-specific antigen levels in nipple aspirate fluid correlate with breast cancer risk. Cancer Epidemiol Biomarkers Prev 1996, 5(12):967-970.

8. Sauter ER, Lininger J, Magklara A, Hewett JE, Diamandis EP: Association of kallikrein expression in nipple aspirate fluid with breast cancer risk. Int J Cancer 2004, 108(4):588-591.

9. Hsiung R, Zhu W, Klein G, Qin W, Rosenberg A, Park P, Rosato E, Sauter E: High basic fibroblast growth factor levels in nipple aspirate fluid are correlated with breast cancer. Cancer J 2002, 8(4):303-310.

10. Qin W, Zhu W, Schlatter L, Miick R, Loy TS, Atasoy U, Hewett JE, Sauter ER: Increased expression of the inflammatory protein YKL-40 in precancers of the breast. Int J Cancer 2007, 121(7):1536-1542.

11. Emami N, Diamandis EP: Utility of kallikrein-related peptidases (KLKs) as cancer biomarkers. Clin Chem 2008, 54(10):1600-1607.

12. Shaw $\mathrm{L}$, Diamandis EP: Distribution of 15 human kallikreins in tissues and biological fluids. Clin Chem 2007, 53(8):1423-1432.

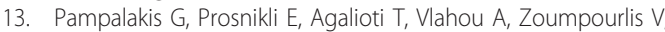
Sotiropoulou G: A tumor-protective role for human kallikrein-related peptidase 6 in breast cancer mediated by inhibition of epithelial-tomesenchymal transition. Cancer Res 2009, 69(9):3779-3787.

14. Schams D: Growth factors in milk. Endocr Regul 1994, 28(1):3-8.

15. Mohanty AK, Singh G, Paramasivam M, Saravanan K, Jabeen T, Sharma S, Yadav S, Kaur P, Kumar P, Srinivasan A, et al: Crystal structure of a novel regulatory $40-\mathrm{kDa}$ mammary gland protein (MGP-40) secreted during involution. J Biol Chem 2003, 278(16):14451-14460.

16. Yan L, Borregaard N, Kjeldsen L, Moses MA: The high molecular weight urinary matrix metalloproteinase (MMP) activity is a complex of gelatinase B/MMP-9 and neutrophil gelatinase-associated lipocalin (NGAL). Modulation of MMP-9 activity by NGAL. J Biol Chem 2001, 276(40):37258-37265

17. Leng $X$, Ding $T$, Lin H, Wang Y, Hu L, Hu J, Feig B, Zhang W, Pusztai L, Symmans WF, et al: Inhibition of lipocalin 2 impairs breast tumorigenesis and metastasis. Cancer Res 2009, 69(22):8579-8584.

18. Bauer M, Eickhoff JC, Gould MN, Mundhenke C, Maass N, Friedl A: Neutrophil gelatinase-associated lipocalin (NGAL) is a predictor of poor prognosis in human primary breast cancer. Breast Cancer Res Treat 2008, 108(3):389-397.

19. van Veen HA, Geerts ME, Zoetemelk RA, Nuijens JH, van Berkel PH: Characterization of bovine neutrophil gelatinase-associated lipocalin. J Dairy Sci 2006, 89(9):3400-3407.

20. Bierie B, Gorska AE, Stover DG, Moses HL: TGF-beta promotes cell death and suppresses lactation during the second stage of mammary involution. J Cell Physiol 2009, 219(1):57-68.

21. Ghellal A, Li C, Hayes M, Byrne G, Bundred N, Kumar S: Prognostic significance of TGF beta 1 and TGF beta 3 in human breast carcinoma. Anticancer Res 2000, 20(6B):4413-4418.

22. Rosfjord EC, Dickson RB: Growth factors, apoptosis, and survival of mammary epithelial cells. J Mammary Gland Biol Neoplasia 1999, 4(2):229-237

23. Pampalakis G, Arampatzidou M, Amoutzias G, Kossida S, Sotiropoulou G: Identification and analysis of mammalian KLK6 orthologue genes for prediction of physiological substrates. Comput Biol Chem 2008, 32(2):111-121.

24. Dorn J, Schmitt M, Kates R, Schmalfeldt B, Kiechle M, Scorilas A, Diamandis EP, Harbeck N: Primary tumor levels of human tissue kallikreins affect surgical success and survival in ovarian cancer patients. Clin Cancer Res 2007, 13(6):1742-1748.

25. Prezas P, Arlt MJ, Viktorov P, Soosaipillai A, Holzscheiter L, Schmitt M, Talieri M, Diamandis EP, Kruger A, Magdolen V: Overexpression of the human tissue kallikrein genes KLK4, 5, 6, and 7 increases the malignant phenotype of ovarian cancer cells. Biol Chem 2006, 387(6):807-811. 
26. Santin AD, Diamandis EP, Bellone S, Soosaipillai A, Cane S, Palmieri M, Burnett A, Roman JJ, Pecorelli S: Human kallikrein 6: a new potential serum biomarker for uterine serous papillary cancer. Clin Cancer Res 2005, 11(9):3320-3325.

27. Slagter MH, Scorilas A, Gooren L, de Ronde W, Soosaipillai A, Giltay EJ, Paliouras M, Diamandis EP: Effect of testosterone administration on serum and urine kallikrein concentrations in female-to-male transsexuals. Clin Chem 2006, 52(8):1546-1551.

28. Tost J, Gut IG: DNA methylation analysis by pyrosequencing. Nat Protoc 2007, 2(9):2265-2275

29. D'Alessandro A, Scaloni A, Zolla L: Human milk proteins: an interactomics and updated functional overview. J Proteome Res 2010, 9(7):3339-3373.

30. Liao Y, Alvarado R, Phinney B, Lonnerdal B: Proteomic Characterization of Human Milk Whey Proteins during a Twelve-Month Lactation Period. J Proteome Res 2011, 10(4):1746-54

31. Peitersen B, Bohn L, Andersen H: Quantitative determination of immunoglobulins, lysozyme, and certain electrolytes in breast milk during the entire period of lactation, during a 24-hour period, and in milk from the individual mammary gland. Acta Paediatr Scand 1975, 64(5):709-717.

32. Anderson DM, Williams FH, Merkatz RB, Schulman PK, Kerr DS, Pittard WB: Length of gestation and nutritional composition of human milk. Am J Clin Nutr 1983, 37(5):810-814.

33. Garza C, Johnson CA, Smith EO, Nichols BL: Changes in the nutrient composition of human milk during gradual weaning. Am J Clin Nutr 1983, 37(1):61-65.

34. Yousef GM, Yacoub GM, Polymeris ME, Popalis C, Soosaipillai A, Diamandis EP: Kallikrein gene downregulation in breast cancer. $\mathrm{Br} J$ Cancer 2004, 90(1):167-172

35. Eissa A, Amodeo V, Smith CR, Diamandis EP: Kallikrein-related peptidase-8 (KLK8) is an active serine protease in human epidermis and sweat and is involved in a skin barrier proteolytic cascade. J Biol Chem 2011, 286:687-706.

36. Planque C, Choi YH, Guyetant S, Heuze-Vourc'h N, Briollais L, Courty Y: Alternative splicing variant of kallikrein-related peptidase 8 as an independent predictor of unfavorable prognosis in lung cancer. Clin Chem 2010, 56(6):987-997.

37. Serra R, Crowley MR: TGF-beta in mammary gland development and breast cancer. Breast Dis 2003, 18:61-73.

38. Hinshelwood RA, Huschtscha LI, Melki J, Stirzaker C, Abdipranoto A, Vissel B, Ravasi T, Wells CA, Hume DA, Reddel RR, et al: Concordant epigenetic silencing of transforming growth factor-beta signaling pathway genes occurs early in breast carcinogenesis. Cancer Res 2007, 67(24):11517-11527.

Pre-publication history

The pre-publication history for this paper can be accessed here: http://www.biomedcentral.com/1471-2407/12/100/prepub

doi:10.1186/1471-2407-12-100

Cite this article as: Qin et al:: Differential expression of cancer associated proteins in breast milk based on age at first full term pregnancy. BMC Cancer 2012 12:100.

\section{Submit your next manuscript to BioMed Central and take full advantage of:}

- Convenient online submission

- Thorough peer review

- No space constraints or color figure charges

- Immediate publication on acceptance

- Inclusion in PubMed, CAS, Scopus and Google Scholar

- Research which is freely available for redistribution

Submit your manuscript at www.biomedcentral.com/submit
Biomed Central 